\title{
The Use of Exaggerative Language in News Articles About Cystic Fibrosis Therapies Exaggerative Language Describing Cystic Fibrosis Therapies
}

J Gen Intern Med 36(5):1437-9

DOI: $10.1007 / \mathrm{s} 11606-020-05768-4$

(C) Society of General Internal Medicine 2020

\section{INTRODUCTION}

When describing novel medical treatments, news articles often use exaggerated language to describe them. Such practices may be particularly problematic if no clinical data exists to provide supporting evidence for these claims. With the increasingly significant role played by Internet-based medical information on screening, clinical decision-making, and overall health outcomes, discretion should be taken to disseminate accurate and unbiased information about pharmaceutical therapies to the public. ${ }^{1,2}$ Because cystic fibrosis (CF) treatments are expensive - Orkambi, for example, is estimated to cost $\$ 272,000$ per year ${ }^{3}$ - and because of novel therapies like Trikafta coming to market, we investigated the use of exaggerated language in news articles covering CF therapies. We also evaluated whether the news sources reporting these stories were compliant with the Health on the Net Foundation Code of Conduct (HONcode) regarding the reliability and credibility of health information.

\section{METHODS}

We performed a cross-sectional analysis modeled after Abola and Prasad. ${ }^{4}$ A search was conducted on Google News for articles published between May 22, 2019, and November 22, 2019, containing "cystic fibrosis treatment" in conjunction with 10 prespecified exaggerative terms: "breakthrough," "cure," "game changer," "groundbreaking," "home run," "life changing," "life-saving," "marvel," "miracle," "revolutionary," and "transformative." Articles were excluded if these terms were not used to magnify a therapy's effectiveness or benefit. The following data were extracted from each news article: the article URL, the name of the news outlet, frequency of superlative(s) use, the $\operatorname{drug}(\mathrm{s})$ or treatment(s) about which the article was written, drug class, whether the treatment received Food and Drug Administration (FDA) approval, whether the news article referenced clinical data, author's background (e.g., physician, journalist), and whether the news article referenced a celebrity in the article. Data were extracted using a pilot-tested Google form in a blinded, duplicate

Received February 25, 2020

Accepted March 4, 2020

Published online June 30, 2020 fashion by two of us (DW and RO). We also investigated the reliability of news articles by searching the websites for registration through HONcode certification (www.hon.ch/HONcode/), an ethical and trustworthy code for medical and healthrelated information available on the Internet.

\section{RESULTS}

Our search returned 260 news articles regarding CF treatment, of which $187(71.9 \%)$ articles from 119 unique news outlets were included. The 187 articles over the 6-month timeframe pertained to 12 different treatment options. The 187 included articles collectively contained a total of 709 exaggerated terms with a mean of $3.79( \pm 1.70)$ per article. The most common term used was "life-saving" (254/709, 35.8\%). The most common drugs associated with exaggerated language were lumacaftor/ivacaftor (Orkambi ${ }^{\circledR} ; 98 / 187,52.4 \%$ ) with 250 terms used in 98 articles, and elexacaftor/tezacaftor/ivacaftor (Trikafta $^{\mathrm{TM}} ; 60 / 187,32.1 \%$ ) with 172 terms used in 60 articles. FDA approval had been granted for half $(50 \%, 6 / 12)$ of the included treatments. In most cases, authors were journalists $(173 / 187,92.5 \%)$. For 6 of the 12 treatments $(50 \%)$, exaggerated language was used in the absence of clinical data in all included articles. Of the 173 articles written by journalists, only $24(13.9 \%)$ contained clinical data. The use of celebrities was not frequent $(16 / 187,8.55 \%)$. Of the 119 news outlets, only 1 was HONcode certified $(1 / 119,0.85 \%)$ (Table 1$)$.

\section{DISCUSSION}

Our study demonstrates that use of exaggerated language is common in news articles covering CF therapies. Four treatments (Trikafta ${ }^{\mathrm{TM}}$, Kalydeco ${ }^{\circledR}$, Symdeko $^{\circledR}$, Orkambi $^{\circledR}$ ) accounted for $89.7 \%$ (636/709) of the use of these exaggerated words, with the most common term being "life-saving." The mean yearly cost of these four drugs is $\$ 296,500$ per year. Thus, this expense may limit the "life-saving" potential for patients who cannot afford them. The Cystic Fibrosis Foundation reports that nearly half of $\mathrm{CF}$ patients pay more than $\$ 5000$ per year, even after the help of charities and payment from insurance companies. ${ }^{5}$ Journalists and physicians should be aware of the effect of exaggerated language on CF patients and families. The HONcode certification is an effective guide when seeking accurate medical information. In one study, only $0.6 \%$ of health websites without HONcode certifications met criteria for HONcode ethical standards compared with $89 \%$ of 


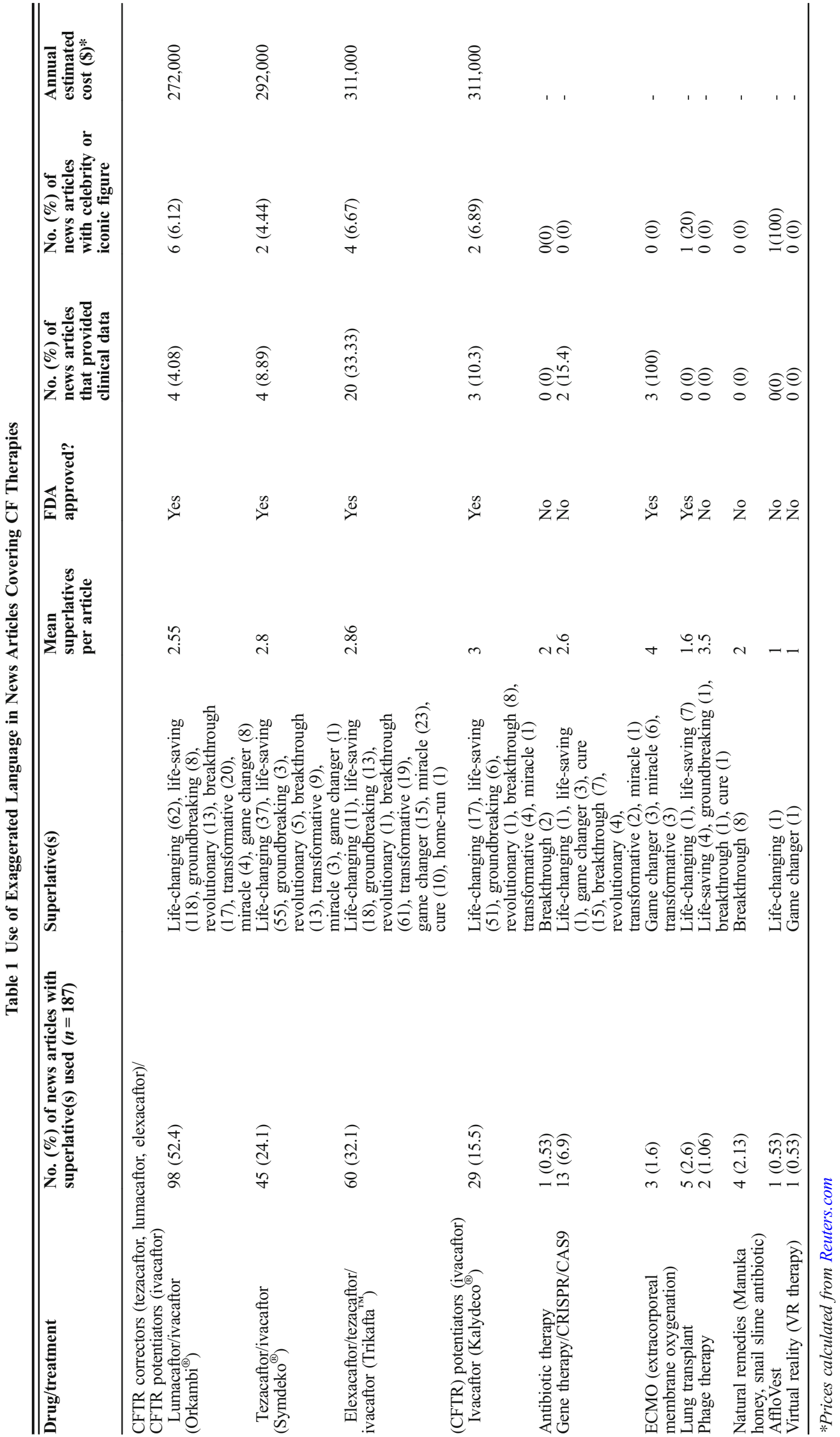


HONcode certified websites. ${ }^{6}$ With only 1 news website registered through HONcode and only $14.4 \%$ (27/187) of included articles providing clinical evidence, the likelihood of CF patients encountering biased medical information is high. We recommend readers searching for health-related information across the medical spectrum use only HONcode certified websites.

David Wenger, BS

Ryan Ottwell, BS

Austin L. Johnson, BS

Trevor Torgerson, BS

Matt Vassar, $\mathrm{PhD}$

Oklahoma State University Center for Health Sciences - Office of Medical Student Research, 1111 W 17th St., Tulsa, OK, 74137, USA

Corresponding Author: David Wenger, BS; Oklahoma State University Center for Health Sciences - Office of Medical Student Research, $1111 \mathrm{~W}$ 17th St., Tulsa, OK 74137, USA (e-mail: david.wenger@okstate.edu).

\section{Compliance with Ethical Standards}

Conflict of Interest: The authors declare that they do not have a conflict of interest.

\section{REFERENCES}

1. Catalan-Matamoros D, Peñafiel-Saiz C. The Use of Traditional Media for Public Communication about Medicines: A Systematic Review of Characteristics and Outcomes. Health Commun. 2019;34(4):415-423.

2. Nabi RL, Prestin A. Unrealistic Hope and Unnecessary Fear: Exploring How Sensationalistic News Stories Influence Health Behavior Motivation. Health Commun. 2016;31(9):1115-1126.

3. Thomas K. A Drug Costs $\$ 272,000$ a Year. Not So Fast, Says New York State. New York, NY. The New York Times. https://www.nytimes.com/ 2018/06/24/health/drug-prices-orkambi-new-york.html. Published June 24, 2018. Accessed February 18, 2020.

4. Abola MV, Prasad V. The Use of Superlatives in Cancer Research. JAMA Oncol. 2016;2(1):139-141.

5. Preserving Access for People with $\mathrm{CF}$ : The Importance of Cost and Affordability. https://www.cff.org/About-Us/Our-Approach-to-FederalState-and-Local-Policy/Policy-Spotlight/Why-Cystic-Fibrosis-Treatmentsand-Care-Need-to-Be-More-Affordable/. Accessed February 10, 2020.

6. Laversin S, Baujard V, Gaudinat A, Simonet M-A, Boyer C. Improving the transparency of health information found on the internet through the honcode: a comparative study. Stud Health Technol Inform. 2011;169:654-658

Publisher's Note: Springer Nature remains neutral with regard to jurisdictional claims in published maps and institutional affiliations. 